\title{
The 'SPARC' of life: Analysis of the role of osteonectin/SPARC in pancreatic cancer (Review)
}

\author{
MONICA K. ROSSI ${ }^{1}$, MANU GNANAMONY ${ }^{1}$ and CHRISTOPHER S. GONDI ${ }^{1,2}$ \\ Departments of ${ }^{1}$ Internal Medicine and ${ }^{2}$ Surgery, University of Illinois College of Medicine at Peoria, Peoria, IL 61605, USA
}

Received December 19, 2015; Accepted January 27, 2016

DOI: 10.3892/ijo.2016.3417

\begin{abstract}
Pancreatic ductal adenocarcinoma (PDAC) is one of the most clinically challenging cancers to manage. An estimated 48,960 people will be diagnosed with pancreatic cancer in 2015 , of that population, $94 \%$ are projected to perish within 5 years. These dismal survival rates can be attributed, in part, to an advanced diagnosis occurring in $80 \%$ of cases. The heterogeneous and dynamic microenvironment of pancreatic cancer, and the lack of both specific risk factors and efficacious screening tools contribute to the challenge of diagnosing pancreatic cancer in its early stages. These clinical challenges have directed research into the unique characteristics that define PDAC. Recently, there has been an increased focus on the interaction of tumor cells with their microenvironment in the hope of identifying new therapeutic targets. One of the most promising avenues in this new vein of research is targeting protein communication between the cancer cells and the extracellular matrix. The secreted protein acidic and rich in cysteine (SPARC) is one such extracellular matrix protein that has shown potential as a therapeutic target due to its influence on PDAC invasion and metastasis. In this review, we discuss the complex interaction of SPARC with PDAC cells and its potential to guide treatment and eventually improve the survival of patients diagnosed with this devastating disease.
\end{abstract}

\section{Contents}

1. Introduction

2. Therapeutic resistance in pancreatic cancer

Correspondence to: Dr Christopher S. Gondi, Department of Internal Medicine, University of Illinois College of Medicine at Peoria, 1 Illini Drive, Peoria, IL 61605, USA

E-mail: gondi@uic.edu

Abbreviations: PDAC, pancreatic ductal adenocarcinoma; SPARC, secreted protein acidic and rich in cysteine; CT, computerized tomography; MRI, magnetic resonance imaging; CSCs, cancer stem cells; ECM, extracellular matrix; PaSCs, pancreatic stellate cells

Key words: SPARC, pancreatic cancer, osteonectin, extracellular matrix, pancreatic ductal adenocarcinoma
3. Pancreatic stellate cells and SPARC

4. SPARC and pancreatic cancer

5. Conclusion

\section{Introduction}

Pancreatic cancer is projected to be the second leading cause of cancer-related deaths in the United States by the year 2030 (1). Pancreatic ductal adenocarcimona (PDAC) is one of the most devastating malignancies worldwide, with a median survival rate of 3-5 months for metastatic and 6-10 months for locally advanced disease (2). These dismal median survival rates have remained consistent over the past three decades (3-5). The heterogeneous and multifactorial nature of pancreatic cancer, further clouded by a lack of specific risk factors, has hindered successful prevention strategies. Tobacco use and obesity are believed to increase a patient's risk of pancreatic cancer by 20-30\% (6,7). Family history, race and gender also contribute to an increased risk of developing PDAC. Approximately $5-10 \%$ of pancreatic cancer patients report a history of pancreatic cancer in their family (8). African Americans are more likely to develop pancreatic cancer than Caucasians and men are $30 \%$ more likely to develop pancreatic cancer than women. Additional identified risk factors include: diets with excessive red meat consumption, alcohol abuse, and type II diabetes (9).

In addition to a wide range of risk factors, pancreatic cancer is exceedingly difficult to diagnose. Patients present with non-specific symptoms and anatomically the pancreas is not palpable on physical examination; leading to an advancedstage PDAC diagnosis in $80 \%$ of cases (10). The lack of effective blood tests and other screening tools for early detection biomarkers has also contributed to the low rate of diagnosis of PDAC in pre-malignant stages. In order to confirm a diagnosis of pancreatic cancer, clinicians must use visualization technology, most commonly, computerized tomography (CT) and magnetic resonance imaging (MRI) scans (11). CT scans are used to identify the presence of pancreatic cancer lesions (12-14) while MRI scans are useful in assessing metastasis and local invasion (15). In addition to CT and MRI scans for diagnosing pancreatic cancer, endoscopic ultrasound provides information about vascular invasion (16), laproscopy is used for more accurate staging (17), and fludeoxyglucose-positron emission tomography scanning is often employed for assessing 
recurrent tumors (18). Despite the success of these technologies in diagnosing pancreatic cancer, none have proven effective as practical screening tools for patients in both general and high-risk populations.

Upon diagnosis with PDAC, a number of chemotherapy and radiation therapy options exist for the patient. However, the dynamic molecular composition of PDAC has nullified the effects of the majority of combination treatments that have proven successful in combating breast and hematologic cancers (19). Therefore, the immediate treatment strategy for PDAC includes surgical resection of the tumor followed by chemotherapy and radiation (20). While surgical resection of pancreatic tumors has been shown to increase survival rates by 10 months in case of stage I and II, the majority of patients that undergo these procedures experience recurrence or an associated co-morbidity (21) mainly due to late detection. In the past decade, pancreatic cancer research has shifted to investigate the unique tumor microenvironment as the source of PDAC therapy resistance (22-26). Decreased angiogenesis, cancer stem cells (CSCs), and dense stromal proliferation are all characteristics of the PDAC microenvironment that now serve as potential targets for future therapies.

Despite improved understanding of pancreatic cancer on a molecular level, overall patient survival rates have remained relatively stagnant (27). In order to advance treatment options and median survival rates of patients, we must first increase our understanding of the therapeutic resistant nature of pancreatic cancer.

\section{Therapeutic resistance in pancreatic cancer}

Cellular mechanisms. The majority of current research into the therapeutic resistance of pancreatic ductal adenocarcinoma (PDAC) is centered on the molecular composition of the pancreatic cancer cells (PCCs) and the surrounding stromal cells. Majority of PDAC cases show accumulation of highly penetrant genetic aberrations at four common genetic loci: the oncogene KRAS (95\% of cases), and the tumor suppressor genes p53 (80\%), CDKN2A (85\%) and SMAD4/DCP4 (50\%) (28). Point mutations in KRAS oncogene result in the constitutive expression of the Ras protein. The Ras protein initiates a signaling cascade that activates proliferative and cell survival pathways thus, increasing the tumor cell's invasive capacity (29-32). TP53 is a tumor-suppressing gene that is inactivated in $\sim 80 \%$ of PDAC cases (28). The inactivation of TP53 leads to an impaired response to DNA damage due to a loss of cell cycle control and the lack of cellular apoptotic signals $(33,34)$. CDKN2A is another tumor suppressor loci and is inactivated in $85 \%$ of PDAC (28). The genes $16^{\text {Ink4a }}$ and $15^{\mathrm{ARF}}$ are encoded at the CDKN2A locus and confer similar cellular malfunction seen with inactivation of TP53 $(35,36)$. DCP4 gene mutations are seen in $\sim 50 \%$ of PDAC and confer a metastatic phenotype (28). While these genetic mutations are responsible for the initiation and invasion of PDAC, the proliferation of the lesion is fostered by the unique microenvironment surrounding the tumor.

The stromal microenvironment. The stroma describes the interstitial tissue surrounding the malignant lesion in pancreatic ductal adenocarcinoma (PDAC) (32). Several stromal components contribute to a dense desmoplastic reaction seen in many epithelial tumors (breast, prostate, ovarian, colorectal) with pancreatic cancer exhibiting some of the most extensive stromal development (37). The desmoplastic reaction encourages tumor invasion, metastasis, and chemoresistance (37-39). In addition to its role in cancer invasiveness, the desmoplastic reaction also contributes to $90 \%$ of the tumor volume by promoting the deposition of extracellular matrix (ECM) (40). Initially, the desmoplastic reaction was thought to serve a protective function (41). However, a more recent study has shown that once the stromal components are activated, they can take on malignant phenotypes and may even contribute to carcinogenesis (38). The negative characteristics of the desmoplastic reaction further complicate treatment options. For example, any 'activated' stroma left behind after resection may encourage proliferation of small numbers of tumor cells missed by the procedure (42). In addition, this inflamed area can act as a barrier to chemotherapy and decrease the efficacy of adjuvant therapy following resection (42). These stromal reactions have also been observed to precede cancer development (43); further highlighting the importance of understanding the composition and molecular biology of the stromal microenvironment.

\section{Pancreatic stellate cells and SPARC}

Pancreatic stellate cells (PaSCs). Since their isolation in 1998 (44), pancreatic stellate cells (PaSCs) have been implicated in the maintenance of tissue architecture through regulation of ECM protein synthesis and degradation. PaSCs have been identified in a variety of organs including liver, kidney, intestine, and spleen (45). In the normal pancreas, PaSCs exist in a quiescent state and are activated in response to damage. Activated PaSCs allow the repair process to occur by triggering fibrosis through various stromal interactions (42). PaSCs are implicated in tumor progression because they secrete proteins that increase cancer cell invasiveness and migration, notably SPARC (42) and periostin (46).

\section{SPARC and pancreatic cancer}

Role of SPARC in PDAC. The secreted protein acidic and rich in cysteine (SPARC), also known as osteonectin or basementmembrane protein 40 (BM-40), is an extracellular matrix glycoprotein that is implicated in the metastatic potential of several cancer types (47). Normal SPARC expression occurs during mammalian development and is ultimately limited to tissues with high ECM turnover, such as gut, epithelia and bone. Wound healing, angiogenesis, and the stroma during tumorigenesis, induce SPARC activity (48). These processes suggest SPARC functions as a regulator of tissue remodeling in healthy cells. The role of SPARC in cancer has been shown to both promote and inhibit tumor progression, depending on the initiating cell type, tumor, stage, and context of the microenvironment (48). For example, in neuroblastoma tumors, SPARC significantly impaired tumor growth by acting as an anti-angiogenic factor produced by the Schwann cells (49). However, in pancreatic ductal adenocarcinoma (PDAC), pancreatic cancer cells (PCCs) induced overexpression of SPARC in PaSCs located in close proximity to malignant 


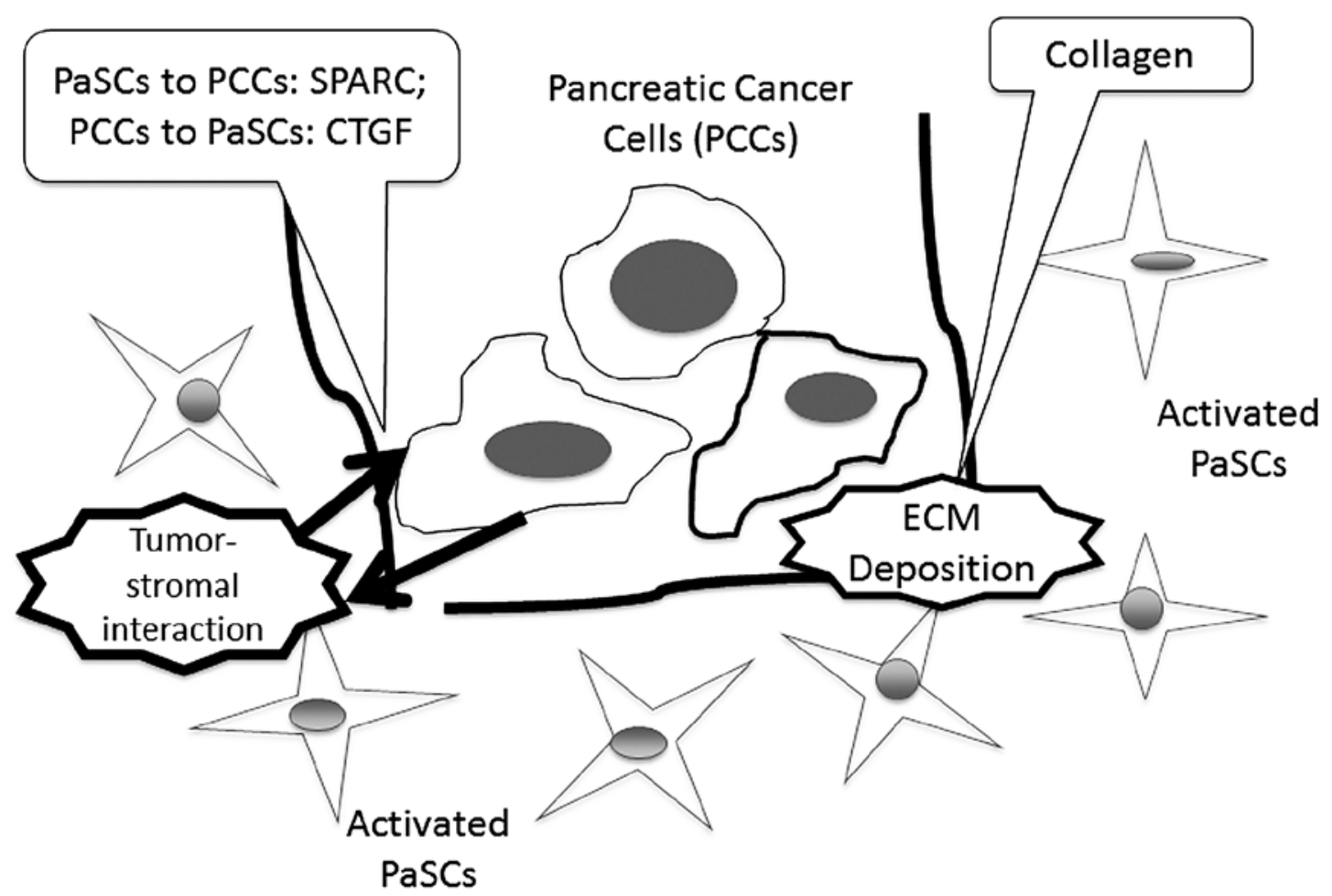

Figure 1. Schematic view of tumor-stromal interaction between PaSC and PCCs. Pancreatic cancer cells (PCCs) change the composition of the extracellular matrix (ECM) by increasing inflammatory cell recruitment and increasing pancreatic stellate cell (PaSC) populations via the connective tissue growth factor (CTGF). PaSCs secrete the secreted protein acidic and rich in cysteine (SPARC) which promotes PCC invasion and metastasis.

tumor cells (50). While at the same time, the PCCs themselves were unable to express SPARC due to aberrant hypermethylation of the $\mathrm{CpG}$ island on their promoter (51). The altered methylation patterns on the SPARC gene were then suggested as a potential biomarker for early PDAC detection (52). A small study evaluating 40 cases of pancreatic cancer, 6 chronic pancreatitis tissues, and 6 acute pancreatitis tissues were analyzed for these methylation patterns (52). The study concluded that aberrant methylation of $\mathrm{CpG}$ region 2 might be an early indication of PDAC development and progression and differentiate malignant tissues from healthy and chronic pancreatitis tissues (52).

SPARC influences growth and invasion of PCCs through a variety of pathways. In primary PDAC, SPARC was expressed in tumor cells and in the surrounding ECM components including fibroblast and endothelial cells (47). This indicates that SPARC may promote tumor infiltration into adjacent pancreatic tissue by affecting tumor-ECM interactions (47). PCCs change the composition of the ECM by increasing inflammatory cell recruitment, and promoting fibroblast proliferation (53), more specifically, increasing pancreatic stellate cell (PaSC) populations (53), which, in turn, secrete SPARC (42). In addition to influencing tumor-ECM interactions, SPARC is known to interact with growth factors, including VEGF and TGF- $\beta$ (47). Overexpression of SPARC directly inhibits VEGF expression in PDAC cells (47). In addition, Notch signaling is suppressed by SPARC (54). Notch and VEGF are involved in numerous aspects of vascular development and angiogenesis (54). The combination of decreased angiogenesis and increased metabolic activity of the surrounding stroma results in a hypoxic environment (55). In PDAC, hypoxia is correlated with both increased tumor growth and metastasis (56). In addition to downregulating VEGF and Notch, SPARC also regulates MMP-2 expression and cytoskeleton architecture in PDAC (47). MMP-2 is a matrix metalloproteinase that has been associated with tumor invasion, metastasis, and early recurrence after PDAC resection (47). MMP-2 is also directly linked to the development of the desmoplastic reaction in PDAC (47), which hinders drug delivery, as discussed earlier (42). While the influence of SPARC on PCCs and the surrounding stroma is being teased out, more research is necessary to understand its contribution to metastasis in PDAC.

In contrast to primary PDAC, metastatic PDAC expression of SPARC was present predominantly in the stroma surrounding and adjacent to the metastatic tumor cells (47). Moreover, SPARC expression in the metastatic tumor cells themselves was below the level of detection (47). This highlights an area of potential future research to investigate whether enhanced expression of SPARC in the ECM of pancreatic tumors act to promote tumor cell invasion or block tumor growth and spread. Mantoni et al showed that patients with resected ampullary cancer and overexpression of SPARC in the stroma lived significantly shorter and had more nodal metastases than those with lower SPARC expression (57). Additionally, the study results showed that SPARC has no influence on radiation survival. The researchers could not confirm any influence of SPARC on clonogenic radiation survival neither exogenous SPARC or after siRNA knockdown of SPARC in hPSC co-cultured with pancreatic tumor cells. SPARC's ability to promote invasiveness and migration in pancreatic cancer monoculture via paracrine signaling from PaSCs enhanced the tumor cell invasiveness. Therefore, the 
study postulates that due to the lack of influence on radiation sensitivity in vitro, it is likely the detrimental effect of SPARC on overall survival is related to the protein's anti-adhesive and invasion-promoting properties (57).

Along the same logic, another experiment showed that downregulation of SPARC expression in PANC-1 cells, which overexpress SPARC, resulted in the decreased invasiveness (47). Therefore, SPARC expression in PCCs, when present, appears to selectively enhance their invasiveness and migratory properties (58). Thus, PCCs that express SPARC appear to have enhanced metastatic virulence. In addition to SPARC expression by PCCs, high levels of SPARC expression are evident in virtually all pancreatic circulating tumor cells (CTCs) (58). This raises the possibility that SPARC significantly contributes to the metastatic spread of PDAC. The same study by Ting et al showed that the most highly enriched CTC-specific transcripts shared by almost all 'classical CTCs' encode ECM proteins, like SPARC (58). When the experimenters knocked down SPARC expression, CTC migration was attenuated (58).

In summary, SPARC overexpression is a hallmark of PDAC with low expression in the cancer cells themselves and high expression in stromal fibroblasts (PaSCs). SPARC expression in the stromal cells is associated with poorer prognosis with median overall survival of 15 vs. 30 months (p>0.001) (57). Whereas SPARC expression in the cancer cells was not associated with prognosis. What remains to be understood is the mechanism for induction of SPARC overexpression in these cell types and what the implications are for treatment.

SPARC's influence on cancer therapy. The implications of SPARC and its influence on metastasis and invasion of PDAC make it a promising biomarker for guiding cancer therapy. Gundewar et al identified SPARC expression as predictive of PDAC's response to gemcitabine (51). The overexpression of SPARC was associated with prolonged survival in the subgroup of patients receiving nab-paclitaxel + gemcitabine (51). A phase I/II trial of 36 patients with previously untreated advanced pancreatic cancer being treated with nab-paclitaxel + gemcitabine exposed a potential link between SPARC expression and treatment efficacy (59). The results of this study showed that higher SPARC expression in the stroma was associated with longer overall survival (17.8 vs. 8.1 months). The molecular results of the study showed that nab-paclitaxel alone and with gemcitabine caused a depletion of stromal stiffness with resultant vasodilation (59). It should be noted that all the patients in this study were treated with nab-paclitaxel + gemcitabine. These results led to a phase III metastatic pancreatic adenocarcinoma clinical trial (MPACT), which compared nab-paclitaxel + gemcitabine vs. gemcitabine alone for treatment of metastatic PDAC (60). The trial involved a SPARC assay to examine samples from metastatic lesions. The results of the study showed no significant association between stromal SPARC level and efficacy in either treatment group (60). In addition, no correlation existed between plasma SPARC levels and efficacy of the adjuvant therapy (60). A preclinical experiment performed on mouse models of PDAC with overexpression and diminished SPARC expression also showed a lack of association between SPARC expression and treatment efficacy (61). However, metastatic lesions are frequently expected to be SPARC negative since they have less stroma. Therefore, these studies cannot rule out the relevance of stroma-targeted therapy to enhance drug delivery of nabpaclitaxel at the primary tumor location in PDAC.

SPARC expression has also been evaluated in postchemotherapy treatment of gastric cancer. The results of the study by Gao et al associated SPARC expression in biopsied post-chemotherapy specimens with increased depth of invasion, lymph node metastasis, and TNM stage (62). The authors suggested two possible explanations. First, the chemotherapy may enrich SPARC-positive gastric cancer cells rather than kill the SPARC-overexpressing gastric cancer cells. The second hypothesis was that the chemotherapy might contribute to cancer cells' inner genetic or phenotypic transformation (62). The association of SPARC expression and prognosis makes it an attractive target for new therapeutic treatments.

SPARC: a target for stromal depletion. SPARC has a high affinity for albumin and, therefore, enhances the uptake of an albumin-based formulation of the taxane, nab-paclitaxel (61). Nab-paclitaxel is transported into the tumor lesion piggy-backed on albumin, which is sequestered by SPARC. The mechanism of delivery is particularly active in cancer tissues, which exhibit high perfusion and metabolic activity (63). By exploiting SPARC's high affinity for albumin, nabpaclitaxel accumulates in SPARC-positive areas. In addition, SPARC expression is correlated with tumor response in both preclinical and clinical models of breast, head, and neck cancers. Therefore, it was hypothesized that the enhanced delivery of nab-paclitaxel would cause 'stromal collapse', a process of stromal depletion bringing tumor cells closer together and increasing vascularity, which would increase delivery and efficacy of chemotherapeutic drugs (63). A phase III study in which 861 metastatic PDAC patients were randomized to receive nab-paclitaxel + gemcitabine weekly for 7 weeks for cycle 1 and then on days 1,8 , and 15 every 4 weeks (cycle 2). The results showed a median overall survival of 8.5 vs. 6.7 months (60).

The success of nab-paclitaxel + gemcitabine leads to the next step of determining if any other potential agents will be successful in combination with the drug. In addition, more drugs targeting the stroma, such as the hedgehog inhibitor GDC-0049 are currently under clinical trials for PDAC (63). A large cohort of studies is underway and a review by Neuzillet et al provides a comprehensive Table of clinical trials evaluating stromal depletion in PDAC as well as a Table citing abstracts for nab-paclitaxel use in PDAC (63).

Does attenuation of SPARC overexpression in cancer cell lines decrease cancer cell migration and invasion? SPARC is highly expressed in multiple cancer phenotypes, including astrocytic gliomas. In fact, SPARC is a central player in the invasive activity of glioma cells under hypoxic conditions (64). Seno et al attenuated SPARC expression by transfecting glioma cells with small interfering RNA (siRNA), a synthetic RNA molecule designed to target mRNA for degradation, and confirmed the downregulation of the proteins with western blot analysis (64). Their results indicated that decreasing SPARC expression inhibits glioma cell migration and invasion in vitro. In addition, suppression of SPARC inhibited glioma cell invasion in a rat brain slice model. Another interesting 
result from the study was the upregulation of SPARC expression following hypoxic stress in glioma cells (64). This suggests that the proteins expressed under hypoxic conditions influence SPARC expression thereby promoting the invasion of hypoxic cells into the normoxic tissue surrounding the tumor. This study is promising for PDAC research because, as previously discussed, hypoxia in PDAC is associated with both an increase in tumor growth and metastasis. Therefore, more PDAC research is needed to evaluate any correlation between SPARC, hypoxia, and metastasis.

Another strategy for attenuating SPARC expression is by employing microRNAs (miRNAs), which are small, noncoding RNA molecules that regulate gene expression. In a study evaluating hepatocellular carcinoma (HCC), SPARC expression was knocked down using miR-29a (65). The proposed target pathway of the miR-29a decrease in SPARC expression was the SPARC-AKT pathway, an important aspect of cell proliferation and survival (65). The researchers confirmed that SPARC siRNA also inhibited HCC cell growth.

In addition to using RNA to target SPARC's contribution to metastasis and invasion, siRNAs have been used to alleviate SPARC's influence on collagen deposition. Zhou et al demonstrated reduced collagen I expression in patients with scleroderma by targeting siRNA for SPARC present in fibroblasts (66). Camino et al also knocked down collagen deposition by using anti-sense RNA against SPARC delivered by adenovirus (67). These studies suggest that attenuating SPARC is sufficient to decrease collagen accumulation in tissues and point to a new direction of research into therapies that alleviate fibrosis in disease. PDAC has a dense, fibrotic microenvironment surrounding the tumor cells and SPARC's role in collagen deposition makes it an attractive target to penetrate this stroma and increase the delivery and efficacy of chemotherapy drugs to the lesion.

\section{Conclusion}

Pancreatic ductal adenocarcinoma (PDAC) is a devastating, molecularly complex disease. The dynamic nature of the microenvironment of the tumor and the mechanism of interaction between the extracellular matrix and the tumor cells poses a daunting task for management of the disease. However, this attribute of PDAC presents an exciting frontier of research into novel therapeutic cancer targets. A better understanding of the molecular composition of PDAC and the surrounding microenvironment has placed SPARC at the forefront of research into innovative PDAC therapies and predictive biomarkers of progression and metastasis. The increase in clinical and preclinical studies on the mechanisms of communication between the tumor cells and surrounding stromal cells is providing a solid foundation for future treatments of PDAC. While certain nuances of SPARC and its efficacy as a therapeutic target are not yet completely understood, the preliminary studies show promise for it contributing to improvement in survival of PDAC patients.

\section{Acknowledgements}

This study was supported by Grant from the William E. McElroy Foundation, Springfield, IL 62794-9264, USA to
C.S. Gondi; and the Carrie M. Craig Medical Student Summer Research Fellowship Program sponsored by the University of Illinois College of Medicine at Peoria, Peoria, IL 61656-1649, USA to M.K. Rossi.

\section{References}

1. Rahib L, Smith BD, Aizenberg R, Rosenzweig AB, Fleshman JM and Matrisian LM: Projecting cancer incidence and deaths to 2030: The unexpected burden of thyroid, liver, and pancreas cancers in the United States. Cancer Res 74: 2913-2921, 2014.

2. Hariharan D, Saied A and Kocher HM: Analysis of mortality rates for pancreatic cancer across the world. HPB Oxf 10: 58-62, 2008.

3. Sener SF, Fremgen A, Menck HR and Winchester DP: Pancreatic cancer: A report of treatment and survival trends for 100,313 patients diagnosed from 1985-1995, using the National Cancer Database. J Am Coll Surg 189: 1-7, 1999.

4. Simard EP, Ward EM, Siegel R and Jemal A: Cancers with increasing incidence trends in the United States: 1999 through 2008. CA Cancer J Clin 62: 118-128, 2012.

5. Siegel R, Naishadham D and Jemal A: Cancer statistics, 2012. CA Cancer J Clin 62: 10-29, 2012.

6. Petersen GM, de Andrade M, Goggins M, Hruban RH, Bondy M, Korczak JF, Gallinger S, Lynch HT, Syngal S, Rabe KG, et al: Pancreatic cancer genetic epidemiology consortium. Cancer Epidemiol Biomarkers Prev 15: 704-710, 2006.

7. Blackford A, Parmigiani G, Kensler TW, Wolfgang C, Jones S, Zhang X, Parsons DW, Lin JC, Leary RJ, Eshleman JR, et al: Genetic mutations associated with cigarette smoking in pancreatic cancer. Cancer Res 69: 3681-3688, 2009.

8. Shi C, Hruban RH and Klein AP: Familial pancreatic cancer. Arch Pathol Lab Med 133: 365-374, 2009.

9. American Cancer Society. American cancer society. Cancer Facts \& Figures 2013. http://www.cancer.org/research/cancerfactsstatistics/cancerfactsfigures2013/. Access date: June 23rd, 2015.

10. Stathis A and Moore MJ: Advanced pancreatic carcinoma: Current treatment and future challenges. Nat Rev Clin Oncol 7: 163-172, 2010.

11. Sheridan MB, Ward J, Guthrie JA, Spencer JA, Craven CM, Wilson D, Guillou PJ and Robinson PJ: Dynamic contrastenhanced MR imaging and dual-phase helical CT in the preoperative assessment of suspected pancreatic cancer: A comparative study with receiver operating characteristic analysis. AJR Am J Roentgenol 173: 583-590, 1999.

12. Horton KM and Fishman EK: Adenocarcinoma of the pancreas: CT imaging. Radiol Clin North Am 40: 1263-1272, 2002.

13. Faria SC, Tamm EP, Loyer EM, Szklaruk J, Choi H and Charnsangavej C: Diagnosis and staging of pancreatic tumors. Semin Roentgenol 39: 397-411, 2004.

14. House MG, Yeo CJ, Cameron JL, Campbell KA, Schulick RD, Leach SD, Hruban RH, Horton KM, Fishman EK and Lillemoe KD: Predicting resectability of periampullary cancer with three-dimensional computed tomography. J Gastrointest Surg 8: 280-288, 2004.

15. Vachiranubhap B, Kim YH, Balci NC and Semelka RC: Magnetic resonance imaging of adenocarcinoma of the pancreas. Top Magn Reson Imaging 20: 3-9, 2009.

16. Tellez-Avila FI, Chavez-Tapia NC, López-Arce G, FrancoGuzmán AM, Sosa-Lozano LA, Alfaro-Lara R, Chan-Nuñez C, Giovannini M, Elizondo-Rivera J and Ramírez-Luna MA: Vascular invasion in pancreatic cancer: Predictive values for endoscopic ultrasound and computed tomography imaging. Pancreas 41: 636-638, 2012.

17. Warshaw AL, Tepper JE and Shipley WU: Laparoscopy in the staging and planning of therapy for pancreatic cancer. Am J Surg 151: 76-80, 1986.

18. Sperti C, Pasquali C, Bissoli S, Chierichetti F, Liessi G and Pedrazzoli S: Tumor relapse after pancreatic cancer resection is detected earlier by 18 -FDG PET than by CT. J Gastrointest Surg 14: 131-140, 2010.

19. Rubin $\mathrm{P}$ and Carter SK: Combination radiation therapy and chemotherapy: A logical basis for their clinical use. CA Cancer J Clin 26: 274-292, 1976.

20. Garrido-Laguna I and Hidalgo M: Pancreatic cancer: From stateof-the-art treatments to promising novel therapies. Nat Rev Clin Oncol 12: 319-334, 2015. 
21. Bilimoria KY, Bentrem DJ, Ko CY, Ritchey J, Stewart AK, Winchester DP and Talamonti MS: Validation of the 6th edition AJCC Pancreatic Cancer Staging System: Report from the National Cancer Database. Cancer 110: 738-744, 2007.

22. Liotta LA and Kohn EC: The microenvironment of the tumourhost interface. Nature 411: 375-379, 2001

23. Fidler IJ: The organ microenvironment and cancer metastasis. Differentiation 70: 498-505, 2002.

24. Sato N, Maehara N and Goggins M: Gene expression profiling of tumor-stromal interactions between pancreatic cancer cells and stromal fibroblasts. Cancer Res 64: 6950-6956, 2004.

25. Sato N, Fukushima N, Maehara N, Matsubayashi H, Koopmann J, $\mathrm{Su}$ GH, Hruban RH and Goggins M: SPARC/osteonectin is a frequent target for aberrant methylation in pancreatic adenocarcinoma and a mediator of tumor-stromal interactions. Oncogene 22: 5021-5030, 2003.

26. Li C, Heidt DG, Dalerba P, Burant CF, Zhang L, Adsay V, Wicha M, Clarke MF and Simeone DM: Identification of pancreatic cancer stem cells. Cancer Res 67: 1030-1037, 2007.

27. Hwang RF, Moore T, Arumugam T, Ramachandran V, Amos KD Rivera A, Ji B, Evans DB and Logsdon CD: Cancer-associated stromal fibroblasts promote pancreatic tumor progression. Cancer Res 68: 918-926, 2008

28. Hansel DE, Kern SE and Hruban RH: Molecular pathogenesis of pancreatic cancer. Annu Rev Genomics Hum Genet 4: 237-256, 2003.

29. Hruban RH, Maitra A and Goggins M: Update on pancreatic intraepithelial neoplasia. Int J Clin Exp Pathol 1: 306-316, 2008.

30. Pellegata NS, Sessa F, Renault B, Bonato M, Leone BE, Solcia E and Ranzani GN: K-ras and p53 gene mutations in pancreatic cancer: Ductal and nonductal tumors progress through different genetic lesions. Cancer Res 54: 1556-1560, 1994.

31. Hezel AF, Kimmelman AC, Stanger BZ, Bardeesy N and Depinho RA: Genetics and biology of pancreatic ductal adenocarcinoma. Genes Dev 20: 1218-1249, 2006.

32 Maitra A and Hruban RH: Pancreatic cancer. Annu Rev Pathol 3. 157-188, 2008.

33. Caldas C, Hahn SA, da Costa LT, Redston MS, Schutte M Seymour AB, Weinstein CL, Hruban RH, Yeo CJ and Kern SE: Frequent somatic mutations and homozygous deletions of the p16 (MTS1) gene in pancreatic adenocarcinoma. Nat Genet 8: 27-32, 1994.

34. Schutte M, Hruban RH, Geradts J, Maynard R, Hilgers W, Rabindran SK, Moskaluk CA, Hahn SA, Schwarte-Waldhoff I, Schmiegel W, et al: Abrogation of the Rb/p16 tumor-suppressive pathway in virtually all pancreatic carcinomas. Cancer Res 57: 3126-3130, 1997

35. Hahn SA, Hoque AT, Moskaluk CA, da Costa LT, Schutte M, Rozenblum E, Seymour AB, Weinstein CL, Yeo CJ, Hruban RH, et al: Homozygous deletion map at 18q21.1 in pancreatic cancer. Cancer Res 56: 490-494, 1996.

36. Yachida S, White CM, Naito Y, Zhong Y, Brosnan JA, Macgregor-Das AM, Morgan RA, Saunders T, Laheru DA, Herman JM, et al: Clinical significance of the genetic landscape of pancreatic cancer and implications for identification of potential long-term survivors. Clin Cancer Res 18: 6339-6347, 2012.

37. Vonlaufen A, Phillips PA, Xu Z, Goldstein D, Pirola RC, Wilson JS and Apte MV: Pancreatic stellate cells and pancreatic cancer cells: An unholy alliance. Cancer Res 68: 7707-7710, 2008.

38. Bissell MJ and Radisky D: Putting tumours in context. Nat Rev Cancer 1: 46-54, 2001.

39. Heldin $\mathrm{CH}$, Rubin K, Pietras K and Ostman A: High interstitial fluid pressure - an obstacle in cancer therapy. Nat Rev Cancer 4 806-813, 2004.

40. Neesse A, Michl P, Frese KK, Feig C, Cook N, Jacobetz MA Lolkema MP, Buchholz M, Olive KP, Gress TM, et al: Stromal biology and therapy in pancreatic cancer. Gut 60: 861-868, 2011.

41. Lunevicius R, Nakanishi H, Ito S, Kozaki K, Kato T, Tatematsu M and Yasui K: Clinicopathological significance of fibrotic capsule formation around liver metastasis from colorectal cancer. J Cancer Res Clin Oncol 127: 193-199, 2001.

42. Moir JA, Mann J and White SA: The role of pancreatic stellate cells in pancreatic cancer. Surg Oncol 24: 232-238, 2015.

43. Moinfar F, Man YG, Arnould L, Bratthauer GL, Ratschek M and Tavassoli FA: Concurrent and independent genetic alterations in the stromal and epithelial cells of mammary carcinoma: Implications for tumorigenesis. Cancer Res 60: 2562-2566, 2000 .
44. Bachem MG, Schneider E, Gross H, Weidenbach H, Schmid RM, Menke A, Siech M, Beger H, Grünert A and Adler G: Identification, culture, and characterization of pancreatic stellate cells in rats and humans. Gastroenterology 115: 421-432, 1998.

45. Geerts A: History, heterogeneity, developmental biology, and functions of quiescent hepatic stellate cells. Semin Liver Dis 21: 311-335, 2001.

46. Kanno A, Satoh K, Masamune A, Hirota M, Kimura K, Umino J, Hamada S, Satoh A, Egawa S, Motoi F, et al: Periostin, secreted from stromal cells, has biphasic effect on cell migration and correlates with the epithelial to mesenchymal transition of human pancreatic cancer cells. Int J Cancer 122: 2707-2718, 2008.

47. Guweidhi A, Kleeff J, Adwan H, Giese NA, Wente MN, Giese T, Büchler MW, Berger MR and Friess H: Osteonectin influences growth and invasion of pancreatic cancer cells. Ann Surg 242: 224-234, 2005.

48. Arnold SA and Brekken RA: SPARC: A matricellular regulator of tumorigenesis. J Cell Commun Signal 3: 255-273, 2009.

49. Chlenski A, Liu S, Crawford SE, Volpert OV, DeVries GH, Evangelista A, Yang Q, Salwen HR, Farrer R, Bray J, et al: SPARC is a key Schwannian-derived inhibitor controlling neuroblastoma tumor angiogenesis. Cancer Res 62: 7357-7363, 2002.

50. Podhajcer OL, Benedetti LG, Girotti MR, Prada F, Salvatierra E and Llera AS: The role of the matricellular protein SPARC in the dynamic interaction between the tumor and the host. Cancer Metastasis Rev 27: 691-705, 2008.

51. Gundewar C, Sasor A, Hilmersson KS, Andersson R and Ansari D: The role of SPARC expression in pancreatic cancer progression and patient survival. Scand J Gastroenterol 50: $1170-1174,2015$

52. Gao J, Song J, Huang H, Li Z, Du Y, Cao J, Li M, Lv S, Lin H and Gong Y: Methylation of the SPARC gene promoter and its clinical implication in pancreatic cancer. J Exp Clin Cancer Res: Mar 26, 2010 29:28. (Epub ahead of print). doi: 10.1186/17569966-29-28.

53. Lunardi S, Muschel RJ and Brunner TB: The stromal compartments in pancreatic cancer: Are there any therapeutic targets? Cancer Lett 343: 147-155, 2014.

54. Gorantla B, Bhoopathi P, Chetty C, Gogineni VR, Sailaja GS, Gondi CS and Rao JS: Notch signaling regulates tumorinduced angiogenesis in SPARC-overexpressed neuroblastoma. Angiogenesis 16: 85-100, 2013.

55. Komar G, Kauhanen S, Liukko K, Seppänen M, Kajander S, Ovaska J, Nuutila P and Minn H: Decreased blood flow with increased metabolic activity: A novel sign of pancreatic tumor aggressiveness. Clin Cancer Res 15: 5511-5517, 2009.

56. Kindler HL, Niedzwiecki D, Hollis D, Sutherland S, Schrag D, Hurwitz H, Innocenti F, Mulcahy MF, O'Reilly E, Wozniak TF, et al: Gemcitabine plus bevacizumab compared with gemcitabine plus placebo in patients with advanced pancreatic cancer: Phase III trial of the Cancer and Leukemia Group B (CALGB 80303). J Clin Oncol 28: 3617-3622, 2010.

57. Mantoni TS, Schendel RR, Rödel F, Niedobitek G, Al-Assar O, Masamune A and Brunner TB: Stromal SPARC expression and patient survival after chemoradiation for non-resectable pancreatic adenocarcinoma. Cancer Biol Ther 7: 1806-1815, 2008.

58. Ting DT, Wittner BS, Ligorio M, Vincent Jordan N, Shah AM, Miyamoto DT, Aceto N, Bersani F, Brannigan BW, Xega K, et al: Single-cell RNA sequencing identifies extracellular matrix gene expression by pancreatic circulating tumor cells. Cell Rep 8: 1905-1918, 2014

59. Von Hoff DD, Ramanathan RK, Borad MJ, Laheru DA, Smith LS, Wood TE, Korn RL, Desai N, Trieu V, Iglesias JL, et al: Gemcitabine plus nab-paclitaxel is an active regimen in patients with advanced pancreatic cancer: A phase I/II trial. J Clin Oncol 29: 4548-4554, 2011.

60. Von Hoff DD, Ervin T, Arena FP, Chiorean EG, Infante J, Moore M, Seay T, Tjulandin SA, Ma WW, Saleh MN, et al: Increased survival in pancreatic cancer with nab-paclitaxel plus gemcitabine. N Engl J Med 369: 1691-1703, 2013.

61. Hidalgo M, Cascinu S, Kleeff J, Labianca R, Löhr JM, Neoptolemos J, Real FX, Van Laethem JL and Heinemann V: Addressing the challenges of pancreatic cancer: Future directions for improving outcomes. Pancreatology 15: 8-18, 2015.

62. Gao YY, Han RB, Wang X, Ge SH, Li HL, Deng T, Liu R, Bai M, Zhou LK, Zhang XY, et al: Change of SPARC expression after chemotherapy in gastric cancer. Cancer Biol Med 12: 33-40, 2015 . 
63. Neuzillet C, Tijeras-Raballand A, Cros J, Faivre S, Hammel P and Raymond E: Stromal expression of SPARC in pancreatic adenocarcinoma. Cancer Metastasis Rev 32: 585-602, 2013.

64. Seno T, Harada H, Kohno S, Teraoka M, Inoue A and Ohnishi T: Downregulation of SPARC expression inhibits cell migration and invasion in malignant gliomas. Int $\mathrm{J}$ Oncol 34: 707-715, 2009.

65. Zhu XC, Dong QZ, Zhang XF, Deng B, Jia HL, Ye QH, Qin LX and $\mathrm{Wu} X Z$ : microRNA-29a suppresses cell proliferation by targeting SPARC in hepatocellular carcinoma. Int J Mol Med 30: $1321-1326,2012$.
66. Zhou X, Tan FK, Guo X and Arnett FC: Attenuation of collagen production with small interfering RNA of SPARC in cultured fibroblasts from the skin of patients with scleroderma. Arthritis Rheum 54: 2626-2631, 2006.

67. Camino AM, Atorrasagasti C, Maccio D, Prada F, Salvatierra E, Rizzo M, Alaniz L, Aquino JB, Podhajcer OL, Silva M, et al: Adenovirus-mediated inhibition of SPARC attenuates liver fibrosis in rats. J Gene Med 10: 993-1004, 2008. 